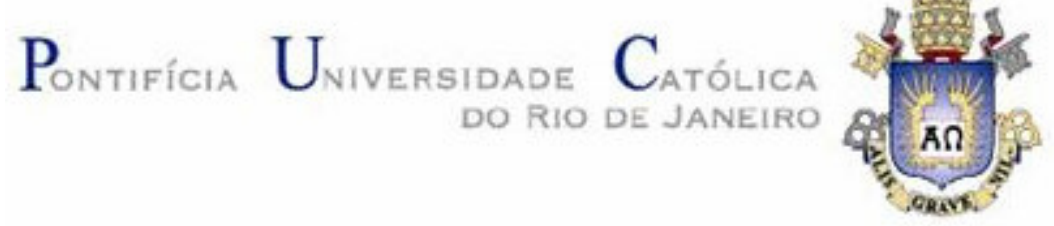

Philipe Deschamps Gonçalves Dias

A diversidade em equipes sob a ótica do gerente de

projetos

Dissertação apresentada ao Programa de Pósgraduação em Administração de Empresas da PUCRio como requisito parcial para a obtenção do título de Mestre em Administração de Empresas.

Orientadora: Profa ${ }^{-}$. Sandra Regina da Rocha Pinto 
Philipe Deschamps Gonçalves Dias

\section{A diversidade em equipes sob a ótica do gerente de projetos}

Dissertação apresentada como requisito parcial para obtenção do grau de Mestre pelo Programa de Pósgraduação em Administração de Empresas da PUCRio. Aprovada pela Comissão Examinadora abaixo assinada.

Profa. Sandra Regina da Rocha Pinto

Orientadora

Departamento da Administração - PUC-Rio

Profa. Ana Heloisa da C. Lemos Departamento da Administração - PUC-Rio

Prof ${ }^{a}$. Úrsula Wetzel

Profa. Mônica Herz

Vice-Decana de Pós-Graduação do CCS

Rio de Janeiro, 26 de março de 2010 
Todos os direitos reservados. É proibida a reprodução total ou parcial do trabalho sem autorização da universidade, do autor e da orientadora.

\section{Philipe Deschamps Gonçalves Dias}

Graduou-se em Comunicação Social na Universidade do Estado do Rio de Janeiro - UERJ, em 2002.

Ficha Catalográfica

Dias, Philipe Deschamps Gonçalves

A diversidade em equipes sob a ótica do gerente de projetos / Philipe Deschamps Gonçalves Dias ; orientadora: Sandra Regina da Rocha Pinto. 2010.

126 f. ; $30 \mathrm{~cm}$

Dissertação (Mestrado em Administração)Pontifícia Universidade Católica do Rio de Janeiro, Rio de Janeiro, 2010.

Inclui bibliografia

1. Administração - Teses. 2. Gerente de projeto. 3. Equipes de projeto. 4. Diversidade. 5. Gestão da diversidade. I. Pinto, Sandra Regina da Rocha. II. Pontifícia Universidade Católica do Rio de Janeiro. Departamento de Administração. III. Título.

CDD: 658 
Aos meus pais e a minha avó Suzel, pela educação e amor de sempre.

À Isadora, pela compreensão e estímulo diários. 


\title{
Agradecimentos
}

\begin{abstract}
"A dor é temporária. Pode durar um minuto, uma hora, um dia ou um ano, mas, por fim, chega o momento em que diminui e desaparece. Porém, se eu desistir, ela dura para sempre, porque o ato de entregar os pontos, por menor que seja, permanecerá sempre comigo. Por isso, quando sinto uma vontade doida de desistir, me faço a seguinte pergunta: com o que prefiro viver, com a dor ou com a consciência torturante de que fui derrotado? Diante de tal questão, sempre dou um jeito de seguir em frente" (ARMSTRONG; JENKINS, 2004, P.231).
\end{abstract}

Escrever uma dissertação não é um processo trivial. Envolve muita pesquisa, dedicação, tempo e suor. Durante o período de produção, vez por outra, o mestrando é acometido por um sentimento similar ao expressado acima pelo lendário ciclista norte-americano Lance Armstrong. A dor relatada pelo esportista pode ser comparada às dificuldades que encontramos pelo caminho. Em nenhum momento, no entanto, pensei em desistir, porque, não tenho dúvida, a sensação de defender uma dissertação com êxito pode ser comparada à conquista de um título no esporte. E, de fato, é: um título. O mestrando, no entanto, não percorre essa estrada sozinho e seria injusto não agradecer às pessoas importantes que me ajudaram nesta caminhada.

Agradeço, portanto:

Aos meus pais, José Dias e Maria Lúcia, pela educação, pelo incentivo, pela orientação, pela confiança e pelas palavras de força em todos os momentos da minha vida. Sem eles eu não teria chegado até aqui.

À minha querida esposa Isadora, que soube compreender todos os momentos difíceis e suportar as seguidas ausências durante esses dois anos de dedicação.

À minha orientadora, professora Sandra Regina da Rocha Pinto, que soube controlar a minha enorme ansiedade em todos os momentos. E o fez sempre de forma prazerosa, com um sorriso nos lábios que nos fortalece e nos anima a seguir em frente. Sempre disponível, atenciosa e acolhedora, ela nos inspira a perseverar em busca do conhecimento. Foi gratificante e enriquecedor tê-la ao meu lado. É um exemplo de professora que cumpre à risca a sua missão. 
Ao igualmente querido professor José Roberto Gomes da Silva, figura magnífica e inesquecível, que me ajudou a escolher o tema e com quem iniciei este trabalho. Ele ficará sempre na minha lembrança como um exemplo de Mestre. Um exemplo de dedicação, de alegria, de amor à academia e ao ensino. Ele certamente deixou o mundo melhor do que encontrou.

Aos entrevistados que gentilmente aceitaram conversar comigo por quase uma hora. Alguns foram tão simpáticos e gentis que me receberam em casa, sem nem me conhecer, incutidos apenas pela satisfação de serem úteis à pesquisa acadêmica.

À PUC-Rio, aos professores do IAG e ao quadro administrativo, pela estrutura, seriedade, competência e profissionalismo.

Aos amigos de turma da universidade, que dividiram comigo a tensão de chegar ao final com a sensação de dever cumprido. Eles certamente tornaram esse desafio muito mais agradável. 


\section{Resumo}

Dias, Philipe Deschamps Gonçalves; Pinto, Sandra Regina da Rocha. A diversidade em equipes sob a ótica do gerente de projetos. Rio de Janeiro, 2010. 126p. Dissertação de Mestrado - Departamento de Administração, Pontifícia Universidade Católica do Rio de Janeiro.

A diversidade em equipes sob a ótica do gerente de projetos tem como objetivo precípuo estudar a percepção dos gerentes de projeto acerca da diversidade em suas equipes de trabalho, analisando, em particular, o modo como eles lidam com as diferentes perspectivas que um ambiente de projetos oferece. A pesquisa de campo, de caráter qualitativo e exploratório, utilizou o método fenomenográfico, partindo de um paradigma interpretativo que se baseia na compreensão do sentido humano, nas maneiras de enxergar um fenômeno particular e nas idéias dos indivíduos a respeito do mundo a sua volta (MARTON, 1981, 1986). Durante julho e agosto de 2009, foram ouvidos 15 gerentes de projeto de diferentes áreas de atuação, formação acadêmica e experiência. A partir das opiniões dos entrevistados, foi realizada uma revisão de literatura sobre as tipologias de diversidade surgidas: de conhecimento e comportamento. O papel do gerente de projeto e a comunicação foram levantados como fatores atenuantes da diversidade. Diante do referencial teórico e das opiniões dos entrevistados, conclui-se que os gerentes de projeto enxergam, primeiramente, as diversidades técnicas, em detrimento de diversidades mais óbvias à primeira vista, como gênero, raça e etnia. Conclui-se, também, que as diversidades de conhecimento e comportamento são benéficas para o desenvolvimento de projetos e para as equipes envolvidas. Um time diverso é mais rico, mais criativo e inovador, pois alimenta diversas visões e perspectivas que diferentes modelos mentais trazem para a resolução de problemas. Por outro lado, a diversidade dos indivíduos pode ocasionar problemas de comunicação e coesão.

\section{Palavras-chave}

Gerente de projeto; equipes de projeto; diversidade; gestão da diversidade. 


\section{Abstract}

Dias, Philipe Deschamps Gonçalves; Pinto, Sandra Regina da Rocha (Advisor). The diversity in teams from the perspective of the project manager. Rio de Janeiro, 2010. 126p. MSc. Dissertation - Departamento de Administração, Pontifícia Universidade Católica do Rio de Janeiro.

The diversity in teams from the perspective of the project manager has the ultimate goal of studying the perception of project managers on diversity in their work teams, analyzing in particular how they deal with the different perspectives that a project environmental offers. In the field research, of qualitative and exploratory nature, we used the phenomenographic method, starting from an interpretive paradigm based on understanding the human sense, the ways of seeing a particular phenomenon and the ideas of individuals about the world around them (MARTON, 1981, 1986). During July and August 2009 we heard 15 project managers from different areas of expertise, academic background and experience. Based on the opinions of these respondents, we carried out a literature review on the typologies of diversity emerged: knowledge and behavior. The role of the project manager and communication have been raised as mitigating factors of diversity. Given the theoretical referential and the opinions of respondents, it appears that project managers see, first, technical diversities rather than the more obvious differences at first sight, such as gender, race and ethnicity. It also appears that the diversities of knowledge and behavior are beneficial to the development of projects and the teams involved. A diverse team is richer, more creative and innovative, since it gathers various visions and perspectives that different mental models bring to solving problems. On the other hand, the diversity of individuals can lead to problems of communication and cohesion.

\section{Keywords}

Project maganer; project teams; diversity; management diversity. 


\section{Sumário}

1 Introdução 12

$\begin{array}{lll}1.1 & \text { O problema de pesquisa } & 12\end{array}$

$\begin{array}{lll}1.2 & \text { Objetivos } & 15\end{array}$

$\begin{array}{lll}1.3 & \text { Delimitação do estudo } & 15\end{array}$

$\begin{array}{lll}1.4 & \text { Relevância do estudo } & 16\end{array}$

$\begin{array}{lll}1.5 & \text { Estrutura da dissertação } & 17\end{array}$

2 Referencial Teórico 18

2.1 O Gerenciamento de projetos - uma rápida apresentação 18

2.2 O gerente de projetos: seu perfil, habilidades e características 22

2.3 O gerente de projetos como um líder na gestão de suas equipes 34

2.4 Comunicação organizacional 39

2.5 A diversidade das equipes de projetos 51

3 Metodologia 66

3.1 Tipo de pesquisa 66

$\begin{array}{lll}3.2 & \text { Seleção dos sujeitos } & 71\end{array}$

$\begin{array}{lll}3.3 & \text { Coleta de dados } & 73\end{array}$

$\begin{array}{lll}3.4 & \text { Tratamento dos dados } & 75\end{array}$

3.5 Limitações do método $\quad 76$

4 Análise e Discussão dos Resultados 77

4.1 Discriminação das tipologias de diversidade 80

4.1.1 Diversidade de conhecimentos $\quad 80$

4.1.2 Diversidade comportamental 90

4.2 Fatores atenuantes da diversidade em equipes de projetos 98

4.2.1 A formação do gerente de projetos 98

$\begin{array}{ll}\text { 4.2.2 O papel da comunicação } & 107\end{array}$ 
5 Considerações Finais 114

$\begin{array}{lll}5.1 & \text { Conclusão } & 114\end{array}$

5.2 Sugestões para trabalhos futuros 118

6 Referências Bibliográficas 119 


\section{Lista de quadros}

Quadro 1 - Habilidades do Gerente de Projetos, segundo Kerzner

Quadro 2 - Habilidades do Gerente de Projetos, segundo Shtub, Bard e Globerson 24

Quadro 3 - Perfil dos gerentes de projetos entrevistados 72

Quadro 4 - Categorias emergentes na pesquisa de campo 78 